\title{
Industrial-educational collaboration case study for fur design education
}

\author{
Nahyun Lee, Nayun Kim, Gahyun Kim and Jisoo Ha* (0)
}

*Correspondence: jisooha@snu.ac.kr Department of Textiles, Merchandising and Fashion Design, College of Human Ecology, Seoul National University, 1 Gwanak-ro, Gwanak-gu, Seoul, Republic of Korea

\begin{abstract}
This paper is a case study on industrial-educational collaboration program between KF and SNU for fur design education. Industrial-educational collaboration program was done by Royal Danish Embassy in South Korea in commemoration of the 55th anniversary of both nations' diplomatic ties. Major tasks of industrial-educational collaboration are as follows. For 3 years from 2014 to 2016, fur design education workshops and fashion shows were held in Seoul of South Korea and Copenhagen of Denmark under mutual cooperation. The goal of a workshop was development of various and creative fur designs along with popularization of fur industry. It has significance in that it contributed to the development of fur industry through creative fur design education for superior students of the world and provided them with opportunities to expand a scope of design through experiencing materials. Future fur industry and global fashion design are expected to develop with much interest and participation through such a successful industrial-educational collaboration program.
\end{abstract}

Keywords: Fur design, Kopenhagen Fur, SNU, Education collaboration

\section{Introduction}

Fur fashion items symbolized social status or wealth until 1990s but has been attacked from animal protection groups continually. Whether fake or natural fur, it is certain that fur is the material always desired by designers owing to its speciality as dress material. Consumers' needs for and recognition on fur have altered in diverse manners by changing socio-cultural and technological environments.

After 2000, with various manufacturing processes and developed techniques, fur material has overcome its limits of material itself and is now acknowledged as a unique fashion item (Skov 2005). Today, fur industry is pursuing trendy and practical design through reflecting fashion trends actively in addition to mix-match with various materials. Recently for several years, young customers preferring fur have increased with its popularity, and it is concentrating on creating customers in their 20-30 s through design stimulating young sensibility based on professionalism of fur design (Fur manufacturer, Target for 20-30's 2012). Young customers are accepting easily fur clothing and accessories as one of fashion trends and such vogue of fur fashion which is new and young is causing increased demand for more creative fur design. However, in regard to its material, special sewing skills and design development technics, different from those of 
general fabric or knit material, are being needed and it is not so easy to form a condition for education specialized in fur in general fashion educational facilities.

For this education, Denmark which has a worldwide scale of fur industry, is leading in supporting the industry transnationally (Melchior et al. 2011). Kopenhagen Fur (KF), a Danish fur industry association, began to select excellent design educational institutions at six nations including South Korea, Japan, China, Denmark, Britain, France in 2014 and nine nations including South Korea, Japan, China, Denmark, Britain, France, Greece, Russia and Kazakhstan in 2015, conclude contracts for industrial-educational collaboration, and implement various workshops and educational programs to develop a variety of creative fur design and cultivate professional designers. Seoul National University (SNU) in South Korea was selected only so industrial-educational collaborations were conducted for students, Dept. of Textiles, Merchandising and Fashion Design, College of Human Ecology in 2014 and 2015, planning to be continued 2016. For 3 years, workshops for fur design education and fashion shows were conducted in Seoul of South Korea and Copenhagen of Denmark under mutual cooperation. The ultimate aim of collaboration by both institutions is popularization of fur industry and development of diverse and creative fur design. That is why the case is worth being reported as fashion industrial-educational collaboration case for its originality. Hence, it has significance in that it aimed to contribute to fur industry development through education for students from the global superior universities to develop various and creative fur design.

Therefore, this paper is a report on successful industrial-educational collaboration programs for fur design at SNU and Kopenhagen Fur during 2014-2015. This paper is expected to encourage successful industrial-educational collaboration.

\section{Academic perspectives of industrial-educational collaboration for fur design education}

The increasing diversity within fashion education simply reflects a steady growth in the mirroring of the wider fashion industry itself (Gale 2012). Recently there have been increasing numbers of industrial-educational collaboration cases (Shin 2015). The topics of previous research were mainly on creativity design education, sustainable design, or 3D apparel CAD (Bill 2012; Lee and Sohn 2011; Pasricha and Kadolph 2009).

The increasement in fashion design education with industry is a positive aspect. However, there are few studies on the development of creative design especially using fur material and collaboration with fur industry which is the core of this paper. Since fur has been considered expensive and unusual material, it has a limitation of accessibility for students and it was rare collabo-rating with fur industry, before the case, the collaboration between KF and SNU.

It is a fact, that although fashion design is often the start point of fashion education, design is only a small part of the wider fashion industry (Gale 2012). Therefore, fashion design education should be carried out with fashion industry. Fur design education and the practical collaboration program with the fur industry can provide students with a wide range of materials to broaden their design scopes and provide a realistic industrial experience. As a result, through this case study, we can expect the global development of the fur design, from the manufacture to disposal as well as development of new fur design curriculum. 


\section{Collaboration process}

Collaboration of SNU with Danish KF was conducted under process of Fig. 1 as follows in South Korea and Denmark.

\section{SNU teacher visiting KF for workshop}

Professors of the Dept. of Textiles, Merchandising and Fashion Design, College of Human Ecology, SNU visited KF, Denmark and participated in fur design development and working before industrial-educational collaboration workshop by KF furriers at SNU.

\section{Pre-workshop for students at SNU}

SNU teachers held a short-term workshop for participant students a week ago KF furriers visited South Korea for workshop. This workshop was held for patterning like a general textile through cutting and trimming the whole mink skin. Teachers instructed for students to work design technic using mink skin as large as possible throughout the process. It aimed to make students familiar with untrimmed mink skin with which they firstly dealt. Also before trimming high quality mink skin to be used at this workshop, relatively law quality mink skin supplied from KF was used for practice.

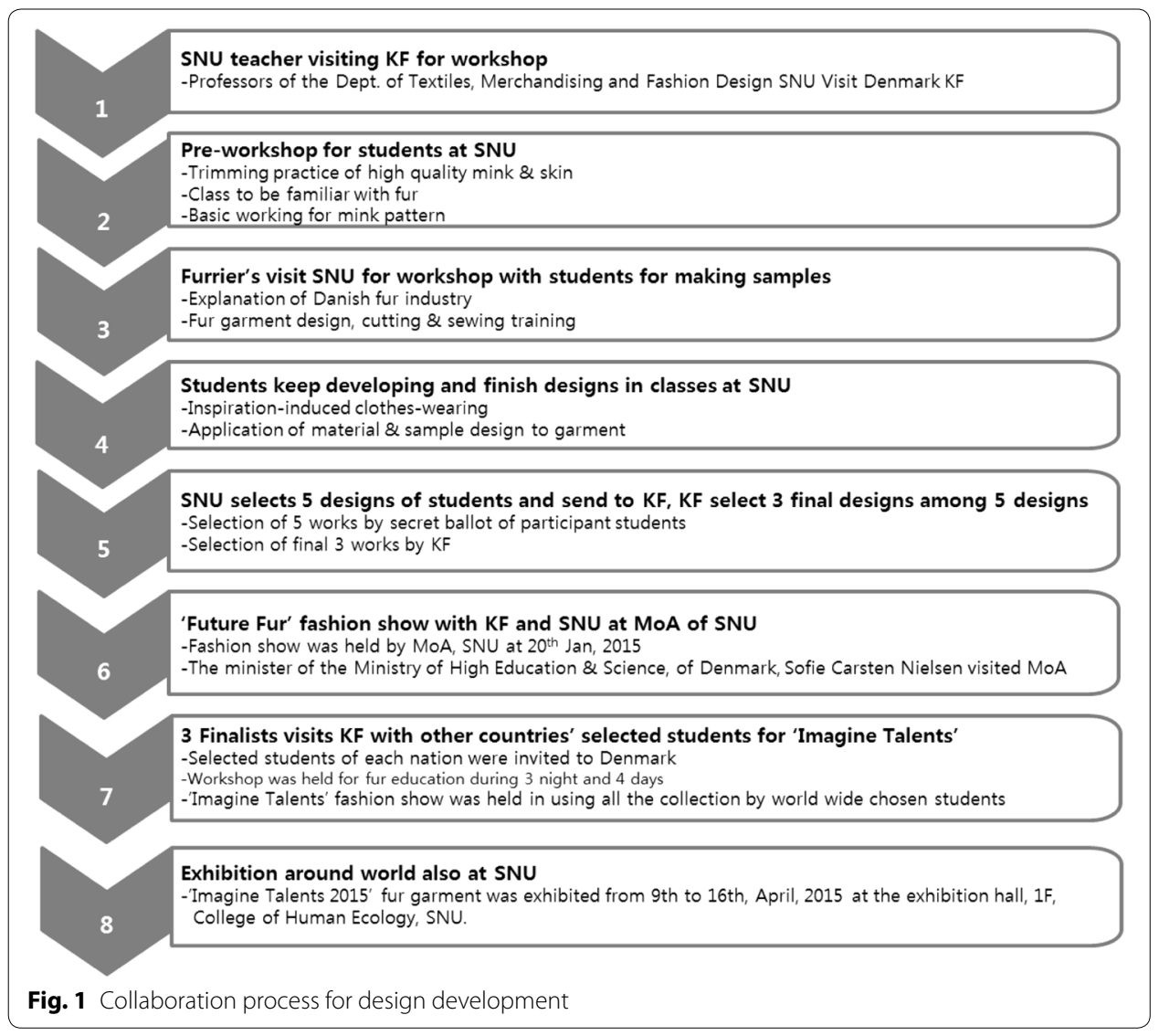




\section{Furriers' visit SNU for workshop with students, making samples}

This workshop was held with 2 KF furriers who visited South Korea at SNU for 4 nights and 5 days along with participant students. Firstly, for students not familiar with fur materials, KF was introduced and its various real fur was shown. KF, a center of the international fur trade, has the largest fur auction house in the world, occupying $40 \%$ of the global mink production (KOPENHAGEN FUR n.d.a, b). There, auction takes place 5 times a year, various materials including about 20 million's mink, fox, Swakara, chinchilla, seal, sable, rabbit and karakul skin are being offered (KOPENHAGEN FUR n.d.a, b). Based on above, material design was developed using various kinds of fur and finally development process of fur garment design was described. Considering its characteristic fur has difference from other general textiles in terms of cutting, sewing and finish, demanding a very complicated and elaborate working. Hence, firstly participant students were educated from furriers about how to treat, cut and sew fur materials with a variety of fur materials including mink, fox produced by KF, as shown from Fig. 2.

And then, students prepared an image of their inspiration and exchanged opinions with KF furriers to develop fur garment design. In particular, to make a design merely they sketched on paper real along with a material they selected, students who encountered fur material firstly concentrated on working with KF furriers in terms of cutting and sewing. As a result, for 4 nights and 5 days, students developed inspiration for their material design, set a design motive and through cutting, sewing and finish of fur, creative fur works were completed using multiple techniques like Fig. 3.

\section{Students keep developing and finish designs in classes at SNU}

Participant students completed works finally through developing and complementing material development technic design from workshop and applying it to a garment. Using completed material development design, sketch of fur garment design was done and students sketched freely wearing and schematization of a garment their inspiration was contained. Sketching was done considering how well their inspiration was expressed and how effectively their fur design technics were applied to garments as the most important elements.

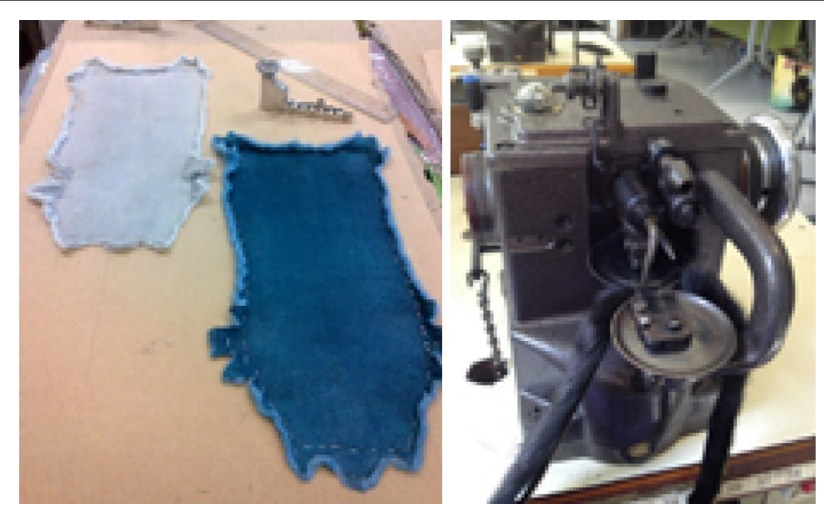

Fig. 2 Working process for fur design development, photographed by the author 

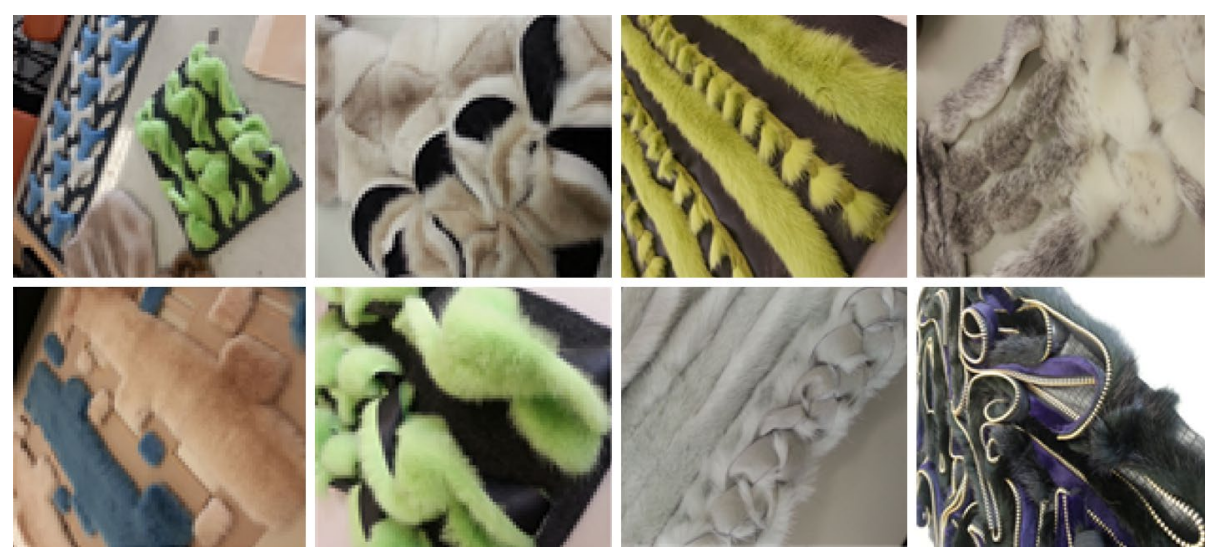

Fig. 3 Final works developed from various fur materials by SNU students, photographed by the author

\section{SNU selects 5 designs of students and send to KF, KF 3 selects final designs among 5}

Participant students had the time for sharing their completed fur garment designs together. They introduced their garment sketch, schematization, inspiration board, actual technic design to other students and selected five works by all students' secret ballot. Five students getting the most votes produced a portfolio based on prior work and sent it to KF. KF selected three works evaluated as the innovative idea and design perfection when producing a real garment.

Students began to produce the real work of the selected design with connection to a local professional fur production. KF was used for every material and students completed the work through active communication and collaboration with the local production from dyeing to cutting and sewing.

Figure 4 shows specific design inspiration, sketches and results.

Design 1 simplified inspiration from trees of Northern Europe into Y-type motives. The entire pattern was completed through connecting their edges. The characteristic of this design is the visible inner side because the parts excepting the joints of $Y$ is empty.

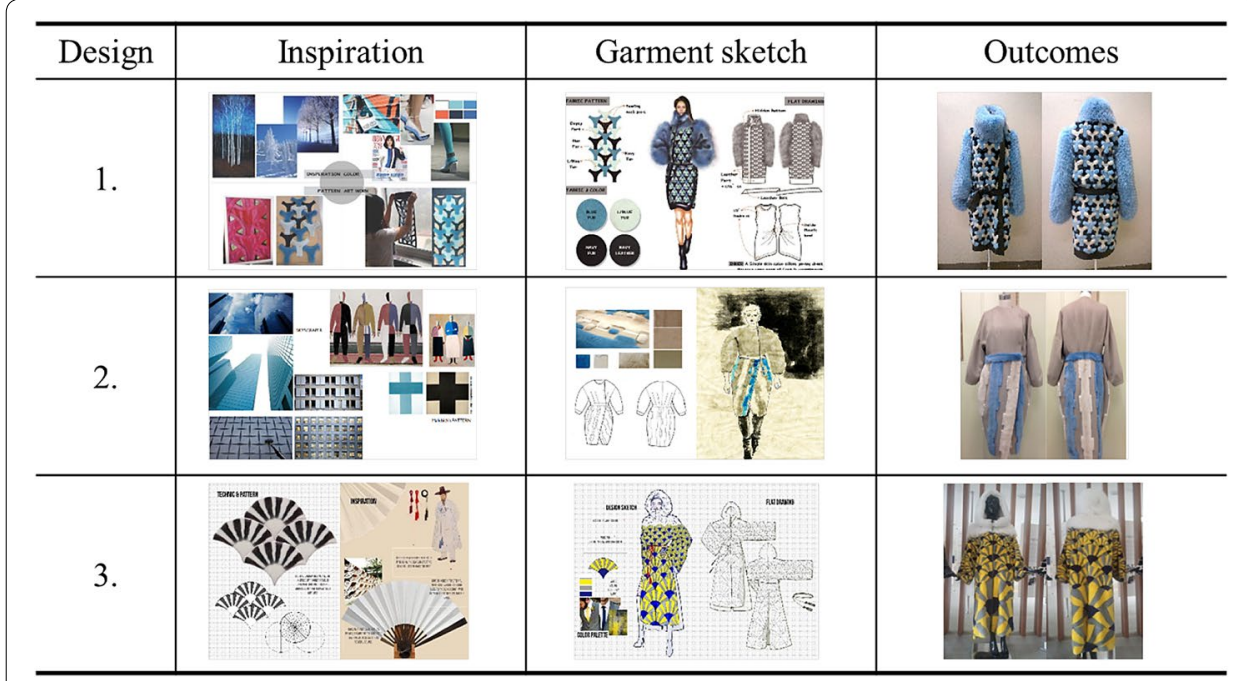

Fig. 4 Process of fur garment design development 
As for color, centered on blue lines, light blue, blue and navy was mixed, as for material, mink were used for a body and fox having abundant volume was used for neck and sleeve, giving a differentiated feeling from the length despite the same color. Besides, leather was mixed partially so more casual and active feeling was added.

Design 2 was inspired by a skyline and a linear form of a skyscraper of a city. It expressed an ambivalent characteristic, say, feeling of flexible fur and that of upright of the building. The entire silhouette was expressed as a form of a round curve for the flexible feeling of fur and the inside fur was cut straightly for the feeling of the skyscraper. Dress color was expressed with a gray tone giving a feeling of the city skyscraper and sky blue, a color of the sky. As for material, tender Alpaca was used for body and mink was added for completion.

Design 3 was inspired by plasticity of the South Korean traditional fan. Even for a single color of the fan, a shadow by wrinkles, when spreading, shows varied colors, becoming the first motive of this work. A fan-shaped motive was arranged repeatedly and composed into three kinds of sizes, the larger it is, the farther down it goes. It was composed of yellow symbolizing light, pale gray symbolizing shadow, and deep blue supporting these two colors harmoniously. Such a design was applied to South Korean traditional male clothes, Dopo. Dopo is a male coat with very wide sleeves and long length covering knees, characteristic of long opening begun from a waistline at both sides and the back with Saejodae, a belt made of the traditional knots (Lee 1977). Every colorful motive was made of mink, and hood of the completed coat was designed with white ample fox fur.

\section{Future Fur fashion show with KF and SNU at MoA of SNU, visiting of the Minister of the Ministry of Education, Denmark}

On 20th, Jan. 2015, 'Future Fur' fashion show was held at MoA of SNU, Gwan-ak Gu, Seoul, under industrial-educational collaboration of SNU and Denmark KF (Figs. 5 and 6). This fashion show was held only in South Korea among 6 participant nations in 2014 and suggested a direction for future fur industry and design through students' works and various kinds of KF garments. Before fashion show, every participant student gave a presentation on their design process during fur design workshop. Many persons participated in such a show with much interest and encouraged their efforts including students and professors, local fur producers, persons concerned in KF, SOFIE CARSTEN

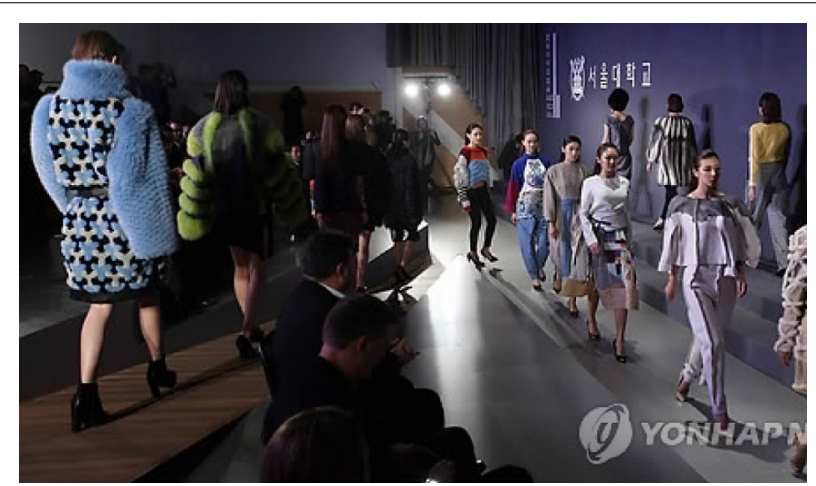

Fig. 5 'Future Fur' fashion show I, photographed by Yonhapnews (2015) 


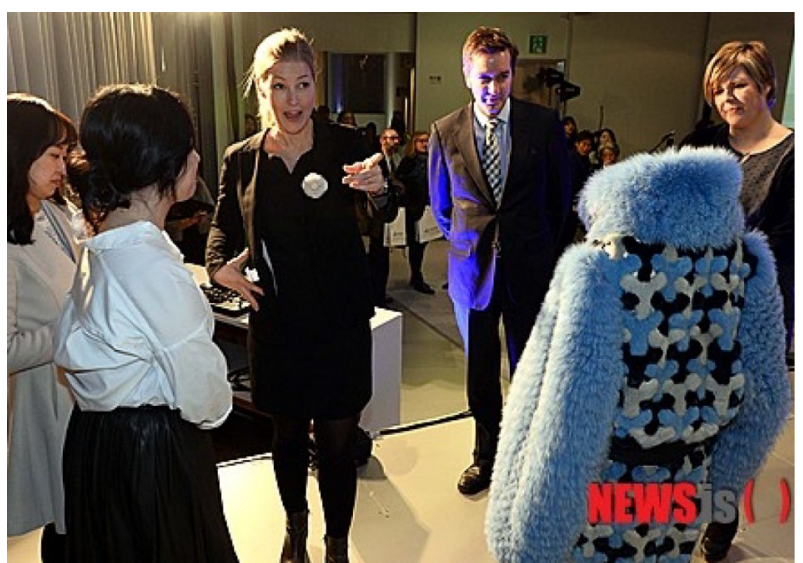

Fig. 6 'Future Fur' fashion show II, photographed by Kim (2015)

NIELSEN, The Minister of the Ministry of High Education \& Science, Thomas Lehmann, Danish ambassador to South Korea, press and magazine editors.

\section{Finalists visits KF with other countries' students for 'Imagine Talents' fashion show}

KF invited students selected finally by nation to Denmark and conducted the 2nd fur educational workshop during 3 nights and 4 days in 2015, 2016. Students from many nations visited $\mathrm{KiCK}$, and introduced and shared their design development and working process (Fig. 7). KiCK is Kopenhagen Fur established the creative power house, KiCK (Kopenhagen International Centre for Creativity) in the heart of Copenhagen in 2013 (KOPENHAGEN FUR n.d.c). KiCK intends to bridge the gap between the fur and fashion industries (KOPENHAGEN FUR n.d.c). By taking the lead in the development of fur fashion, KiCK wants to help create momentum and growth in the fashion industry and within the creative (KOPENHAGEN FUR n.d.c).

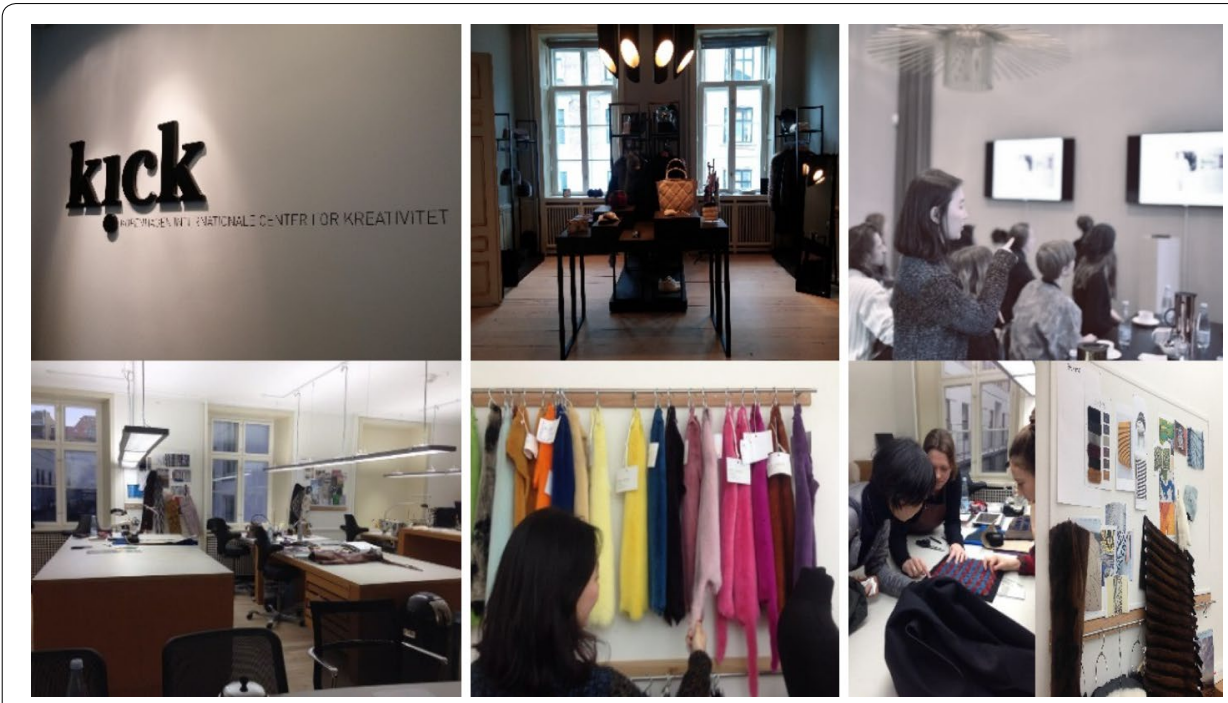

Fig. 7 Introduction and sharing of design development and working process at KiCK, photographed by the author except for 3rd picture in the upper line from WFUR (2015) 
In addition, they saw various kinds of fur garments, accessories and furniture manufactured and sold by KiCk, and had the time to learn from and exchange with designers at the local fur design workroom, working and material development process.

Next, they visited a mink farm for fur manufactured by KF and experienced a fur production process directly (Fig. 8). In particular, the impressing thing was for producers to prioritize welfare of a mink in the entire production process. Fur is obtained from living animals so cherished and respected much.

Finally, they visited the head office of KF where fur is manufactured as a product from the farm and the auction house where commercialized materials are distributed globally (Fig. 9). KF takes pride in its high quality so keeps rules strictly in fur production with modern mechanization in many part. However, in the work requiring the manual necessarily, it was very interesting that experienced masters are specially treated than those of other works. Through such a field trip, students could understand the entire industrial processes of fur including production and distribution.

As the most significant event during 3 nights and 4 days stay, KF held 'Imagine Talents' fashion show within 2015, 2016, Copenhagen Fashion Week (Fig. 10). This fashion show was the important event where participant students from many nations displayed their work, and SOFIE CARSTEN NIELSEN, the Minister of the Ministry of High Education \& Science, parties concerned in fur in the world, fashion magazine editors participated with much interest in the fashion show. With students' creative designs, it was evaluated as the fashion show that presented new design inspiration and a direction for future fur industry while assessing results of workshop program.

\section{Exhibition around world also at SNU}

This exhibition was held with fur works from 'Imagine Talents 2015' from 9th to 16th, April, 2015 at the exhibition hall, 1F, College of Textiles, Merchandising and Fashion
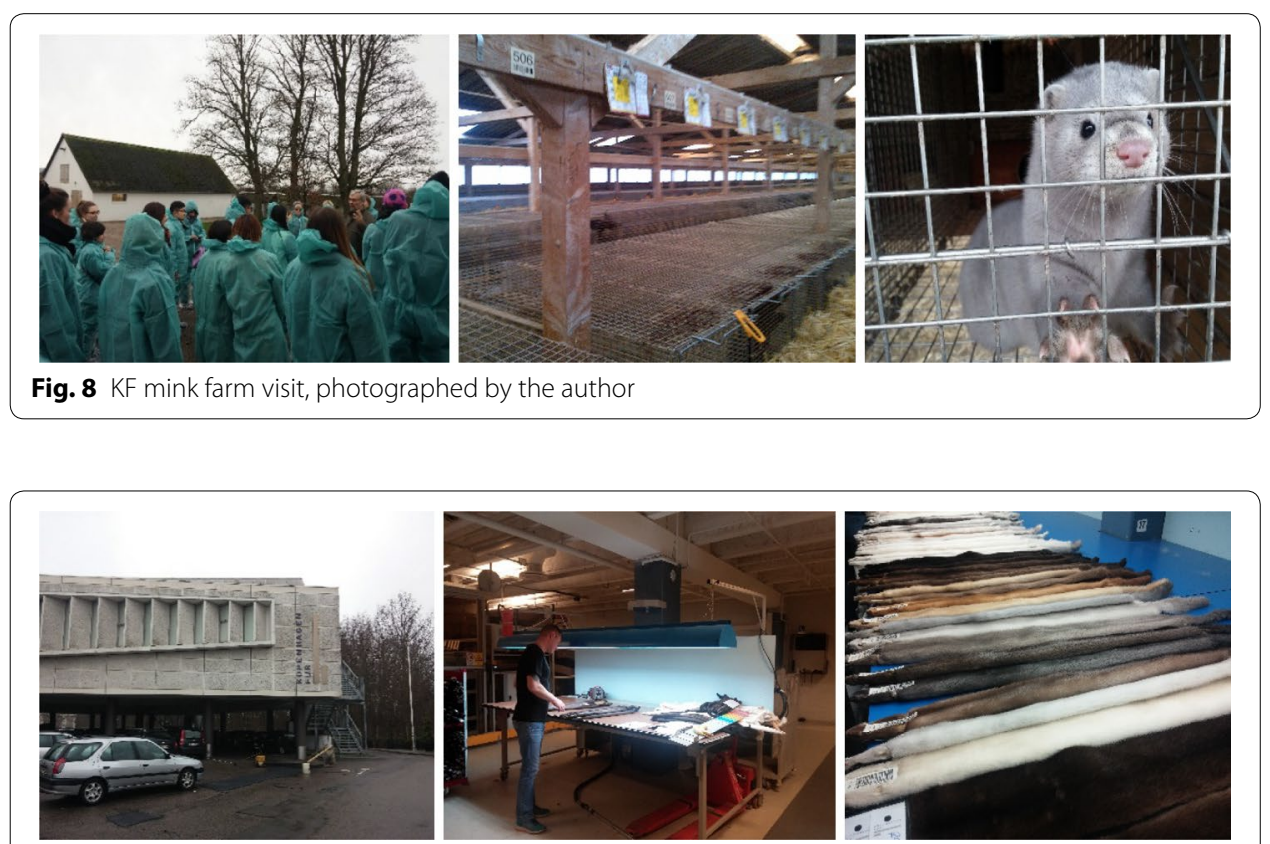

Fig. $9 \mathrm{KF}$ auction house, photographed by the author 


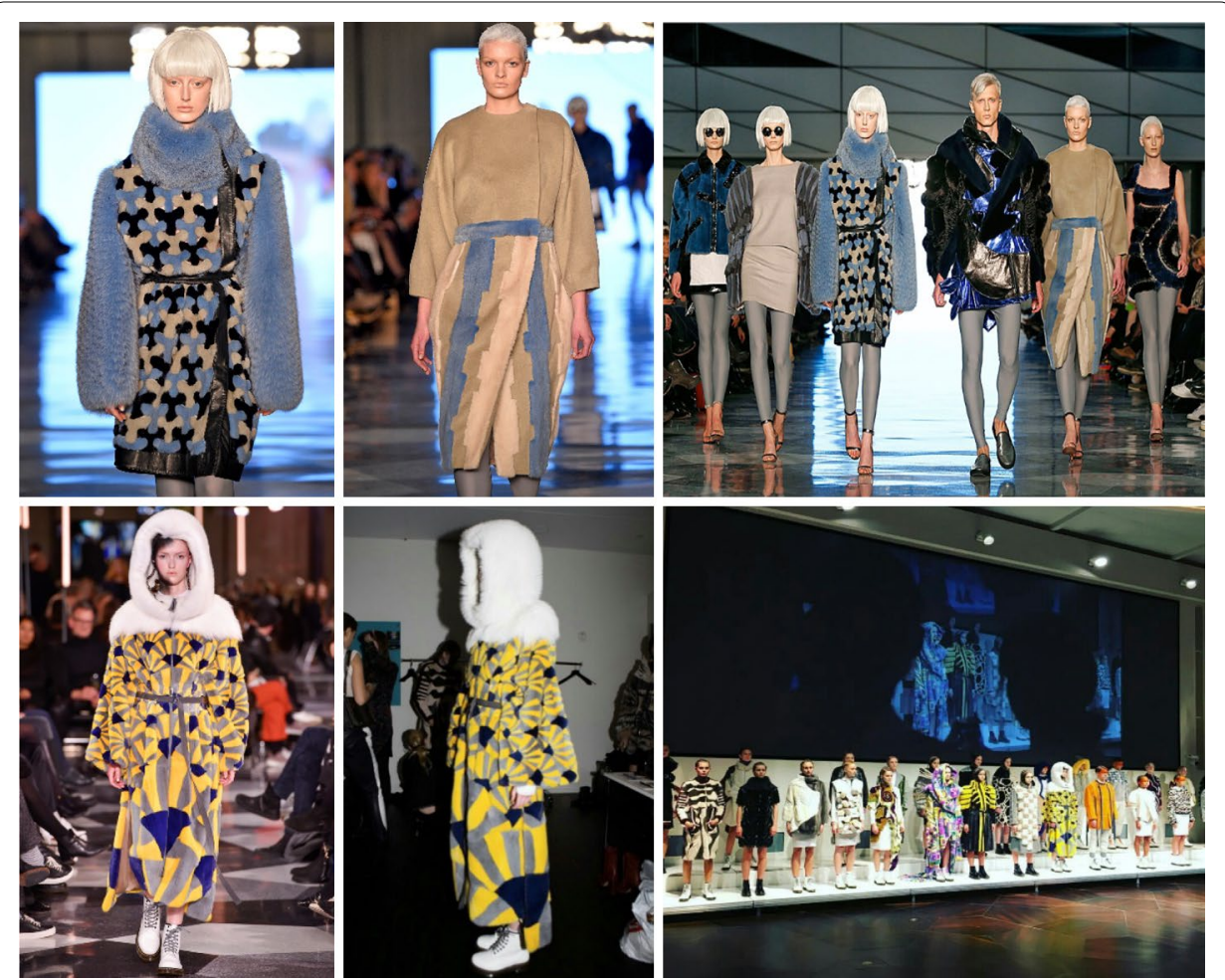

Fig. 10 'Imagine Talents' fashion show at Denmark, photographed by KF

Design, SNU (Fig. 11). About 800 persons saw this exhibition with much interest including students majoring in Clothing and Textiles, SNU, students majoring in various fields of other schools also with professors. In particular, student works from 5 nations were exhibited firstly in addition to those of SNU students, arousing interest from viewers. Besides, on the wall of the exhibition hall, video of 'Imagine Talents Show 2015' held in Copenhagen was played, making viewers feel a fur fashion show scene vividly. Finally, this exhibition increased students' recognition on creative fur design. Also it gave an opportunity to have much interest in collaboration of SNU and KF hereafter.

\section{Future directions}

Positive outcomes from the educational program for fur design development under collaboration between SNU and KF are as follows.

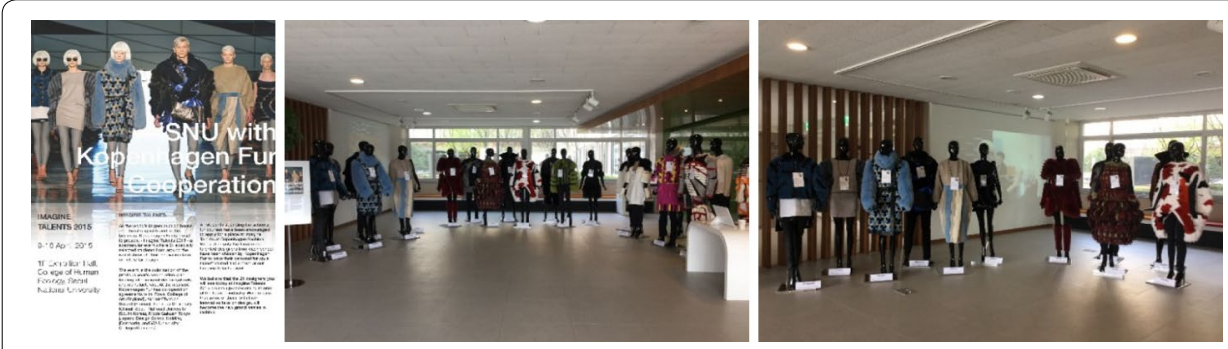

Fig. 11 'Imagine Talents 2015'fur garments exhibition at SNU, photographed by the author 
Firstly, from an educational perspective, it provided students studying fashion design with global-scale experience as well as with valuable experience through experiencing special fur materials not available to them usually and working with professional technicians for design development. Such experience expanded design limitation to a new material in addition to fur for students. Also, it was a precious opportunity to learn craftsmanship of furriers and became a desirable starting point for prospective designers with enhanced inspiration through seeing practical production process of the fur industry system directly, participating in overseas fashion show and exchanging with foreign students.

Secondly, from an industrial perspective, it contributed greatly to positive impact on global fur industry, which encounter stagnation, by long-term marketing and PR of KF, Danish industrial activation. Besides, it gave an opportunity that creative ideas of multicultural students could be realized through its technology and support beyond the KF design limitation to material development. Hence, the company's continual investment and education were greatly activated to cultivate professional furriers.

Thirdly, from an ethical education perspective, during a 3 night 4 day workshop in Copenhagen, students could realized the sustainable industry system in terms of living organism. When using controversial fur materials produced from animals, they rejected a waste of fur in processes of fur procuration and design. Particularly, they always emphasized minimization of fur loss when cutting and sewing. It was helpful for flexible thinking about animal protection issues without fixed stereotype. Also, they showed a firm attitude to enhance the value of fur itself rather than its price. It may be a model case that allows present and prospective fashion designers to reconsider ethical values they should have when using fur in the fashion industry. Generally, it's very important for designers to save materials, not using genuine fur for animal protection. And the opportunity can be used to open a new chapter for more creative and animal protection design by using faux fur.

Fourth, academically it is very essential to report collaboration with industry like the case of the KF and the universities of each country for building and planning on the creative design education program of the future based on the practical cooperation. Academic reports about design education programs can help to establish a basic framework for design collaboration programs with other areas for future. Furthermore, we can further develop this to cater to the active communication and collaboration between fashion industry and fashion education.

Followings are several suggestions to push the collaboration to the limit on a longterm basis.

Firstly, KF collaborate with more than 10 world-class schools but students from different nations fail in sharing information each other for their designs skill they show their works on the same catwalk. Creative design comes from multi-cultural perspectives and students should be encouraged strongly and demanded more communication and networking. Having a basis of diverse cultures is make students possible exchange various kinds of design ideas in design process. Hence, workshops where students from each nation assemble together or on-line meetings using 'Skype' should be arranged rather than one gathering in Denmark at the end. 
Secondly, it should develop key-role player for the close link between Danish and Korean practitioners and technicians in fur industry to lead prosperous trade relationship between countries in terms of fur industry. When manufacturing fur costumes based on students' designs, domestic and Kopenhagen Fur technicians communicate with each other continually and discuss various materials, dyeing and sewing technics for creative designs. Such process allows them to share information and know-hows they have more planning regarding to the communication such as forum or workshop is needed to build more solid communication bonds between them.

Thirdly, the students' works which have been showed in Copenhagen Fashion Week should have more spotlight worldwide. As well as the exhibition tour they are doing, fashion show tour on the catwalk of Milan, New York, London, Shanghai and Seoul are needed to be planned. That will lead the direct opportunity for the collaboration results to meet the real consumers.

So far the collaboration gets high praise in terms of three aspects, which are Danish material promotion, South Korean creative students education and the closer friendship between South Korea and Denmark. One year long distance communication, 3 nights and 4 days trip to Copenhagen, one-week workshop in Seoul and several events are not enough to understand Fun industry and design technic but the collaboration is an essential key enough to make something happen.

Consequently, long-term investments and supports are required continually to cultivate specialized talents in the future fashion industry rather than short-term investments in and momentary attention to MOU program of design school and industry. Through such efforts, it is expected that many students will be concerned and participate in the creative and new fashion industry and design development to open another door for future design.

Authors' contributions

GK carried out theortical studies and case analysis. NK and NL participated in the sequence alignment and drafted the manuscript. JH organised whole collaboration generally. All authors read and approved the final manuscript.

Competing interests

The authors declare that they have no competing interests.

Funding

This work was supported by BK21 Plus project of the National Research Foundation of Korea Grant funded by the Korean government [Grant Number 22B20130000043].

Received: 12 August 2016 Accepted: 27 February 2017

Published online: 28 June 2017

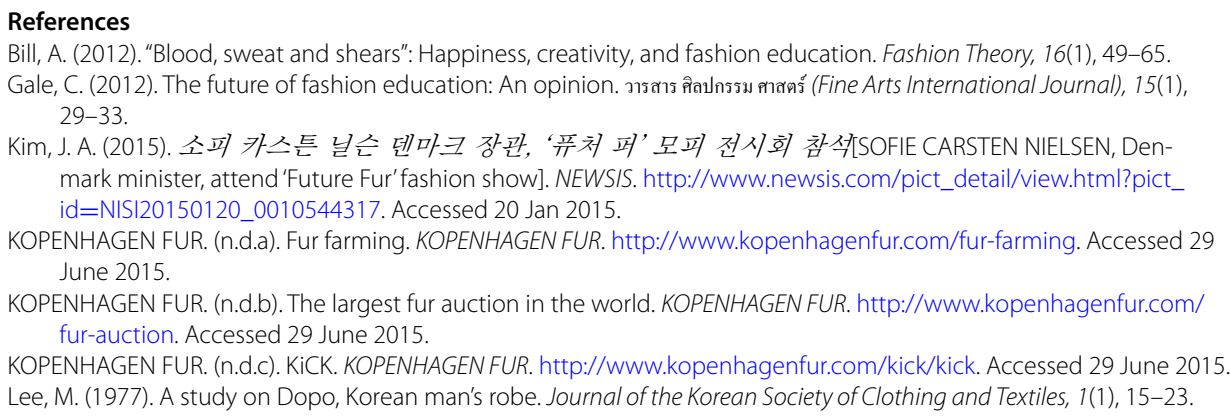


Lee, M. J., \& Sohn, H. S. (2011). A study on the cases of the application of 3D apparel CAD system to the domestic and overseas fashion education. Journal of the Korean Society of Clothing and Textiles, 35(9), 1112-1124.

Melchior, M. R., Skov, L., \& Csaba, F. F. (2011). Translating Fashion into Danish. Culture Unbound, 3, 209-228.

Pasricha, A., \& Kadolph, S. J. (2009). Millennial generation and fashion education: a discussion on agents of change. International Journal of Fashion Design, Technology and Education, 2(2-3), 119-126.

Shin, H.S. (2015). 한국패션실용전문학교, 콜라보레이션 수업 위해500 여개 업체와 MOU 체결 [Korea Fashion Practical School Sign MOU with 500 companies for Collaboration Class]. KNS. http://www.kns.tv/news/articleView. html?idxno=203384. Accessed 30 July 2015.

Skov, L. (2005). The return of the fur coat in a commodity chain perspective. Current Sociology, 53(1), 9-32.

모피 업체, 2030 세대 공략[Fur manufacturer, Target for 20-30's]. (2012). Korea Fashion Association. http://www.koreafashion.org/info/info_news_view.asp?cataldx=104\&boardld=fsNews\&clientldx=11200\&num=5916\&pageNum=5 70\&Srchltem=\&SrchWord. Accessed 19 Apr 2015.

WFUR. (2015). Imagine talents day two. WFUR. http://www.welovefur.com/imagine-talents-day-two/. Accessed 1 Feb 2015.

Yonhapnews. (2015). '퓨처 퍼(Future Fur)' 패션쇼 ['Future Fur'fashion show]. Yonhapnews. http://www.yonhapnews. co.kr/photos/1990000000.html?cid=PYH20150120089100013\&input=1196m. Accessed 20 Jan 2015.

\section{Submit your manuscript to a SpringerOpen ${ }^{\circ}$ journal and benefit from:}

- Convenient online submission

Rigorous peer review

- Immediate publication on acceptance

- Open access: articles freely available online

- High visibility within the field

- Retaining the copyright to your article

Submit your next manuscript at $\gg$ springeropen.com 